\title{
The effect of consumption of garlic tablet on proteins oxidation biomarkers in postmenopausal osteoporotic women: A randomized clinical trial
}

Fereshte Ahmadian ${ }^{1}$, Hassan Mozaffari-Khosravi², Mohammad Hossein Azaraein ${ }^{3}$, Reza Faraji ${ }^{4}$, Javad Zavar-

$$
\text { Reza }^{5}
$$

${ }^{1}$ M.Sc., Department of Biochemistry, Faculty of Medicine, Shahid Sadoughi University of Medical Sciences, Yazd, Iran

${ }^{2}$ Ph.D., Department of Nutrition, Faculty of Health, Shahid Sadoughi University of Medical Sciences, Yazd, Iran

${ }^{3}$ M.Sc., Student Research Committee, Shahid Sadoughi University of Medical Sciences, Yazd, Iran

${ }^{4}$ Ph.D., Kermanshah Cardiovascular Research Centre, Kermanshah University of Medical Sciences, Kermanshah, Iran

${ }^{5}$ Ph.D., Department of Biochemistry, Faculty of Medicine, Shahid Sadoughi University of Medical Sciences, Yazd, Iran

\section{Type of article: Original}

\begin{abstract}
Background: Osteoporosis (OP) is one of the most prevalent metabolic bone diseases at higher ages, especially in postmenopausal women.

Objective: To determine the effect of consumption of garlic tablet on proteins oxidation biomarkers in postmenopausal osteoporotic women.

Methods: The present study was a double-blind randomized controlled clinical trial that included 42 postmenopausal women in Yazd during 2014-2015. Osteoporotic women were randomly assigned into two groups: the garlic group (GG) and the placebo group (PG). Participants in GG took two garlic tablets daily for 1 month and the participants in PG took placebo tablets in the same manner. After 30 days, the plasma level of carbonyl groups (PCO), total antioxidant capacity (TAC), and advanced oxidation protein products (AOPPs) were assessed by spectrophotometric assays. Also, Malondialdehyde (MDA) content was measured according to the procedure of Thiobarbituric Acid (TBA). Data were analyzed by SPSS version 18, using paired-samples ttest, independent-samples t-test, Wilcoxon, and Mann-Whitney U test.

Results: This study showed that garlic tablets had decreased PCO plasma levels $(47.37 \pm 5.98$ vs. $19.62 \pm 3.40 \mathrm{nM}$, $\mathrm{p} \leq 0.001$, before and after the study, respectively), AOPPs $(738.95 \pm 151.86$ vs. $585.12 \pm 209.99 \mu \mathrm{M}, \mathrm{p} \leq 0.008$, before and after the study, respectively), and increased TAC ( $11.34 \pm 10.80$ vs. $47.93 \pm 17.80, p \leq 0.001$, before and after the study, respectively). The parameters in placebo groups showed no significant differences before and after the study, respectively. The levels of MDA before taking the drug in comparison to before Garlic group was also reduced ( $1.30 \pm 1.04$ vs. $0.92 \pm 0.81 \mu \mathrm{M}, \mathrm{p}=0.01$, before and after the study, respectively).

Conclusion: The role of oxidative stress in the pathophysiology of many diseases such as osteoporosis has been demonstrated. The present study showed that garlic consumption can reduce the oxidative stress.

Trial registration: The protocol of trial was registered at the Iranian clinical trial register (www.irct.ir) with ID: IRCT138811183273N1.

Funding: This study funded by Shahid Sadoughi University of Medical Sciences (Yazd, Iran).

Keywords: Oxidative stress, Osteoporosis, Garlic tablets
\end{abstract}

\section{Introduction}

Osteoporosis (OP) is a silent dangerous disease associated with lifestyle. OP causes fractures which can be mortal or disabling, and increases health care expenses (1). In 1991, the World Health Organization (WHO) announced OP as

\section{Corresponding author:}

Javad Zavar-Reza, Faculty of Medicine, Shahid Sadoughi University of Medical Sciences, Yazd, Iran.

Tel: +98 9125028742, Fax: 0098 3535231421, Email: jzavar@ssu.ac.ir

Received: February 07, 2017, Accepted: August 30, 2017, Published: November 2017

iThenticate screening: August 31, 2017, English editing: October 07, 2017, Quality control: October 15, 2017

(C) 2017 The Authors. This is an open access article under the terms of the Creative Commons Attribution-NonCommercialNoDerivs License, which permits use and distribution in any medium, provided the original work is properly cited, the use is non-commercial and no modifications or adaptations are made. 
the fourth health-threatening factor after cancer, myocardial infarction and cerebrovascular disease (2). So, developing OP prevention strategies became one of the main goals of physicians, particularly nutritionists (3). It is estimated that about 61 million people will suffer from OP by the year 2020 (4). Without promotion in preventive strategies, its costs could rise to over 200 billion dollars by 2040 (5). Annually, about 1.5 million fractures occur in osteoporotic patients in the United States (6). OP begins in the fourth decade of life and is more common in women. One out of three females, one out of 12 males, half of the women older than 45 years, and $90 \%$ of $75+$ year-old women develop OP (7). The main cause of the higher prevalence of this disorder in the female population is menopause and reduction in sexual steroid levels which lead to bone turnover and reduced bone density (8). Other underlying factors associated with OP are low mineral density like CA, protein and vitamin D deficiency, smoking, thyroid diseases, low level of sexual hormone, rheumatoid arthritis (RA), diabetes mellitus (DM), Cushing disease, Body index less than 10\% than when at a younger age, body mass index (BMI) lower than 19, alcoholism, malnutrition and certain drugs (such as corticosteroids, furosemide, heparin and phenytoin (9). One of the biggest factors associated with OP is oxidative stress. Under normal conditions, the levels of free radicals such as reactive oxygen species (ROS) are maintained at low levels by and antioxidant systems (enzymes and chemical compounds) in biological systems. If an imbalance between free radicals and antioxidants, referred to as oxidative stress, occurs in the body (10), sex hormones (estrogens and androgens) can influence the growth and structure of the skeleton. So estrogen depletion at menopause in elderly women can cause the development of osteoporosis (11). There is some evidence showing the correlation between oxidative stress and loss of bone density (12). Some studies revealed that estrogen deprivation in menopause increases oxidative stress and bone loss (13). Sendur et al. confirmed the role of oxidative stress over bone density in OP with a study conducted on 45 women in the postmenopausal period (14). On the other hand, estrogen and other chemical therapies have their own complications and can increase the risk of some malignancies, so, extensive efforts have been made to find an effective treatment with the lowest side-effects. Herbal medicine proposed garlic as a treatment of bone loss process due to low estrogen level (15). Garlic is an antioxidant plant and its role in many diseases (like hyperlipidemia [HLP], DM, hypertension [HTN], malignancies) was proved in previous studies (16). Vazquez-Prieto et al. revealed its impact on reducing oxidative stress and vascular cell adhesion molecule-1imperssion in rats (17). A study confirmed that garlic extract antioxidant capacity can effectively decrease oxidative stress (18). As oxidative stress has an important role in OP and garlic has phytoestrogens and anti-oxidative effects, this study investigated the efficacy of garlic tablet in oxidative stress indexes in menopausal women with osteoporosis.

\section{Material and Methods}

This double-blinded study was conducted as a clinical trial on 42 menopausal women referred to the Milad Center for bone mass densitometry in Yazd during 2014-2015. An informed written consent was received from each patient. They could freely leave the study at any time during the study. All patients were continuing their previous medical treatments and no interruptions were made. Research Ethics Committee of SSUMS approved research proposal of the study. The protocol of trial was registered at the Iranian clinical trial register (www.irct.ir) with ID equal IRCT138811183273N1. Inclusion criteria included: proved OP (femoral or lumbar bone mass index lower than $2.5 \mathrm{~g} / \mathrm{cm}^{2}$ ), and being aged between 45 and 65 years. Exclusion criteria included patients with heart diseases, HTN, HLP, gastric ulcer, drug use (aspirin, captopril and anticoagulants) a history of allergic reaction for garlic, and dermatitis. Informed written consent was obtained from all participants. Patients were randomly divided into case and control groups using random block method. In the case group, women received 2 garlic tablets daily with meals for one month and the control group received the same shaped tablet as placebo. Garlic tablets (Garlet) contained $1200 \mu \mathrm{g}$ Alcin equal to $2 \mathrm{~g}$ fresh garlic and the placebo was obtained from Amin Industry, Esfahan, Iran. Before and after intervention, $5 \mathrm{cc}$ of venous blood sample were obtained in non-fasting condition. Samples were frozen in $-70^{\circ}$ C. Plasma protein carbonyl (PCO), advanced oxidation protein products (AOPP), and total antioxidant capacity (TAC) (with 2, 2-diphenyl-1-picrylhydrazyl [DPPH] oxidation) were measured with the following methods: Walwadkar (19), Kataaha et al. (20), Girbal et al. (21), Kitajima (22) and Janaszewska et al. (23). Ikatsu (MDA) measurement was performed by thiobarbituric acid (TBA) (24). Data were coded and entered into SPSS version 18 (SPSS Inc., Chicago, Illinois, USA). Kolmogorov-Smirnov test was used to determine the cases normality. Inferential statistical analyses performed in this study were paired-samples t-test, independent-samples t-test, Wilcoxon, and Mann-Whitney U test. P-values less than 0.05 were considered significant. An informed written consent was received from each patient. They could freely leave the study. All patients were continuing their previous medical treatments and no interruptions were made. The Research Ethics Committee of SSUMS approved research proposal of the study. 


\section{Results}

Forty-two women participating in this study were divided into two groups (Figure 1). Demographic characteristics of patients are summarized in Table 1. As table 1 showed at the beginning of the study, there was no significant difference between the averages of the baseline characteristics in two groups. Serum protein peroxidation measurements are shown in Table 2. Mean PCO level was significantly lower in the garlic group before and after intervention $(p<0.001)$, and there was also a significant difference between the two groups $(p<0.001)$. TAC mean level was lower before than after Garlet tablet administration $(\mathrm{p}<0.001)$. Also, the mean TAC level was significantly different between the two groups $(\mathrm{p}<0.001)$. AOPP level was higher before intervention $(\mathrm{p}=0.02)$ and this difference was significant between the groups $(\mathrm{p}=0.008)$. Moreover, MDA was reduced significantly after garlic treatment $(\mathrm{p}=0.01)$. However, no difference was observed in the control group $(\mathrm{p}=0.39)$.

Table 1. Baseline characteristics of groups under study

\begin{tabular}{|l|l|l|l|}
\hline Characteristics & Garlic group $($ Mean \pm SD) & Placebo group (Mean \pm SD) & p-value \\
\hline Age (year) & $56.10 \pm 5.81$ & $57.27 \pm 5.84$ & 0.51 \\
\hline Age of menarche (year) & $13.55 \pm 0.95$ & $13.68 \pm 1.39$ & 0.72 \\
\hline Age of menopause (year) & $48.55 \pm 4.40$ & $48.22 \pm 5.38$ & 0.83 \\
\hline BMI $\left(\mathrm{kg} / \mathrm{m}^{2}\right)$ & $27.27 \pm 2.58$ & $27.59 \pm 2.93$ & 0.51 \\
\hline BMD in lumbar spine $\left(\mathrm{g} / \mathrm{cm}^{2}\right)$ & $3.28 \pm 0.60$ & $3.28 \pm 0.83$ & 0.98 \\
\hline BMD in neck femur $\left(\mathrm{g} / \mathrm{cm}^{2}\right)$ & $1.91 \pm 0.90$ & $3.28 \pm 0.82$ & 0.91 \\
\hline
\end{tabular}

Table 2. Comparison of oxidation proteins and lipids products before and after intervention in garlic group and placebo group

\begin{tabular}{|l|l|l|l|l|}
\hline \multicolumn{2}{|l|}{ Variables } & Garlic group $($ Mean \pm SD) & Placebo group (Mean \pm SD) & p-value \\
\hline PCO $(n M)$ & Before & $47.37 \pm 5.98$ & $43.61 \pm 7.35$ & 0.079 \\
\cline { 2 - 5 } & After & $19.62 \pm 3.40$ & $42.48 \pm 11.58$ & 0.001 \\
\cline { 2 - 5 } & p-value & 0.001 & 0.92 & \\
\hline \multirow{3}{*}{$\begin{array}{l}\text { TAC }(\% \text { DPPH } \\
\text { Reduction) }\end{array}$} & Before & $11.34 \pm 10.80$ & $11.69 \pm 7.77$ & 0.07 \\
\cline { 2 - 5 } & After & $47.93 \pm 17.80$ & $16.64 \pm 8.15$ & 0.001 \\
\cline { 2 - 5 } & p-value & 0.001 & 0.92 & 0.08 \\
\hline \multirow{3}{*}{ AOPP $(\mu \mathrm{m})$} & Before & $738.95 \pm 151.86$ & $736.50 \pm 95.69$ & 0.02 \\
\cline { 2 - 5 } & After & $585.12 \pm 209.99$ & $666.03 \pm 208.22$ & 0.72 \\
\cline { 2 - 5 } & p-value & 0.008 & 0.16 & 0.01 \\
\hline \multirow{3}{*}{ MDA $(\mu \mathrm{m})$} & Before & $1.30 \pm 1.04$ & $1.28 \pm 1.08$ & \\
\cline { 2 - 5 } & After & $0.92 \pm 0.81$ & $0.39 \pm 1.50$ & \\
\cline { 2 - 5 } & p-value & 0.01 & & \\
\hline
\end{tabular}

44 postmenopausal osteoporotic women

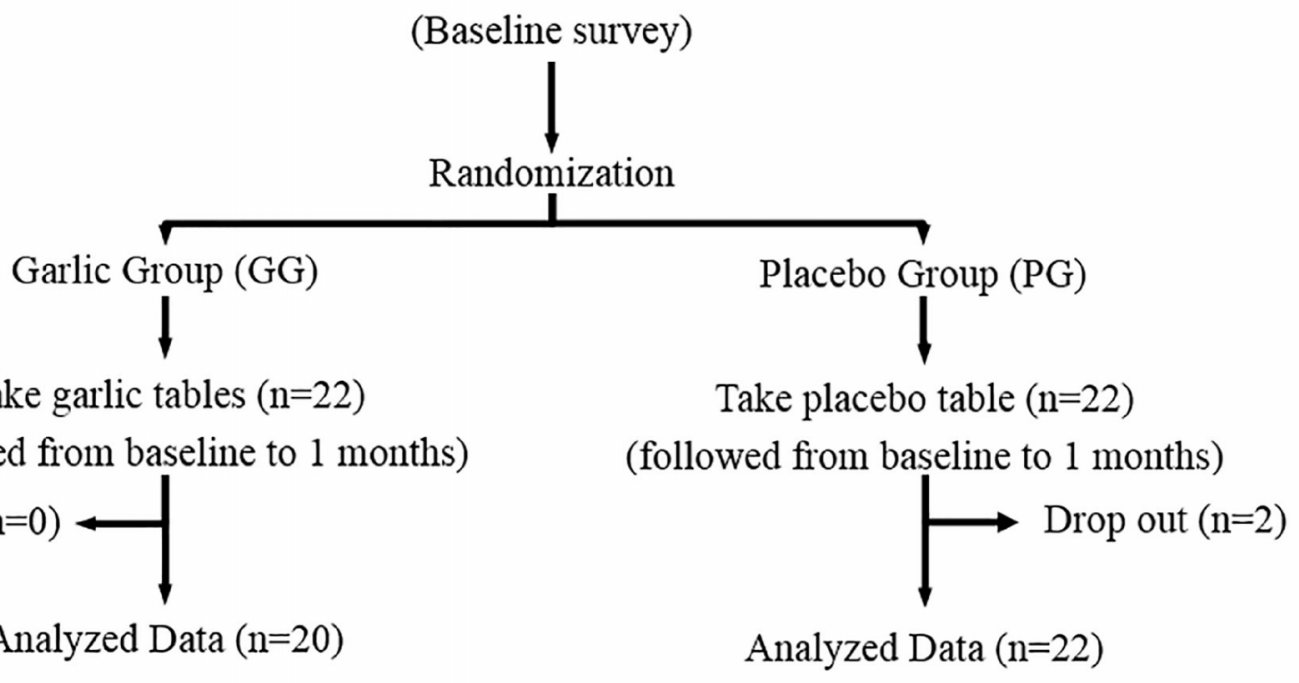

Figure 1. Flowchart of study design and sampling scheme 


\section{Discussion}

Osteoporosis is a bone metabolic disorder in women, particularly in post-menopausal ones. Chemical drugs administration and estrogen therapy have their own side-effects. The traditional medicine and new advantages in herbal drugs reveal the role of medicinal herbs on oxidative stress reduction; onion, ginger, Nigella sativa, Berberis vulgaris extract. In this study, we showed the beneficial effect of garlic tablet on lipid and protein oxidation markers in post-menopausal osteoporosis. The beneficial effects of garlic against oxidative stress are numerous: Garlic decreases NADPH oxidase activity and VCAM-1 expression and therefore decreases inflammation.. Inflammation has a strong association with oxidative stress (17). The S-allyl cysteine (DAS) and s-allyl methyl cysteine (DADS) are the main components of garlic that have high antioxidant properties. DADS can protect osteoblasts from reactive oxygen species (ROS) formation. DADS can protect osteoblasts from reactive oxygen species (ROS) formation in smokers (22). Also, according to the past studies, these results could be due to allicin (inhibits down regulation of the c-Jun N-terminal Kinase Signaling Pathway and so, cell adhesion molecules expression), the protective role of S-allyl cysteine, in oxidized-LDL formation and inhibition of activation of nuclear factor kappa B activated by or hydrogen peroxide. However, some recent studies have been mentioned the anti-inflammatory effect of quercetin (another flavonoid in onion with antioxidant activity) (25-27). Quercetin can attenuate the TNF-alpha and NO production (28). Garlic extract has the anti-hypertrophic and anti-apoptotic role on the myocardial cell (29). As in some recent studies, our study confirmed that garlic tablet can prevent PCO incidence in menopausal women (30). Lai et al. showed that DADS of garlic can prevent problems associated with fatty liver by inhibiting oxidative stress in obese mice (32). Our findings revealed that garlic tablet reduced AOPPs levels in patients. Avci et al. proposed the efficacy of garlic in reducing AOPPs, osteoporosis, and oxidative stress in 66 rats exposed to mobile radio frequency waves (33). The animal study by Sun et al. on rats, showed that AOPPs can prevent bone stem cells proliferation and differentiation, and it might be important in osteoporosis process (34). Zeng et al. proposed that AOPPs accumulation in old mice, increases bone destruction most probably by activation of NADPH oxidase, and also by inhibition of bone reabsorption which has a great role in osteoporosis development (35). In this study, free radical-trapping capacity was statistically different between groups and there was a significant difference before and after garlic tablet administration. Muhammad et al. evaluated oxidative stress in rats after ovariectomy and observed that ovariectomy leads to osteoclasts and osteoblasts proliferation, and bone regulation antioxidant administration such as vitamin E can increase osteoblasts, so improve bone density indices (36). Leain et al., in their study showed that ROS has a negative correlation with estrogen and increases in rats and mice after ovariectomy which activates osteoclasts and suppresses osteoblasts (37). The study by Ehnert et al. assessed cell culture of osteoblasts derived from the femoral bone head of smokers and showed that garlic oil can prevent oxidative stress and promote their activity. They found that DADS was more effective compared to DAS in ROS reduction (38). Mukherjee et al. showed that garlic oil can reduce oxidative stress in lymphocytes and macrophages by estrogen levels compliance in rats and also antioxidant and interleukins increase can protect bone density. They suggested that garlic has a preventive role in bone mass reduction (39). Our study confirmed that MDA (results from the oxidative breakdown of polyunsaturated fatty acids) was reduced significantly after garlic administration. Free radicals' formation occurs in physiologic and pathologic conditions in mammal tissue (40), which react with polyunsaturated fatty acids and produce lipid peroxidation. Fatty oxidation reaction requires the attack to free bases of polyunsaturated fatty acids. Lipid damage occurs after double bond allelic base formation. Weak double bonds can combine with oxygen and produce lipid peroxide base, while lipid peroxide decomposes to aldehyde (like MDA). This component can attach to cellular lipid, protein or Deoxyribonucleic acid (DNA) and lead to structural change (41). Avci et al. showed that garlic can reduce MDA in plasma, red blood cells, and this herb also decreases oxidation reaction and increases antioxidant enzymes (33). Garlic neutralizes the effect of estrogen reduction with calcium absorption. Some reports showed anti-osteoporotic effects of garlic by the preventive role of biomarkers of estrogen deficiency and bone mass decrease and also serum alkaline phosphatase levels $(7,8)$.

\section{Conclusions}

Regarding the findings our study and previous ones, it can be concluded that garlic-derived medicine or raw garlic can be used in osteoporosis to perform calcium absorption. It also might have a great impact on carbonyl groups, AOPPs, and ROS. Garlic influences osteoporosis by oxidative stress reduction. In our study, increased oxidative stress index such as free radicals was observed in the garlic-treated group but it was reduced in the carbonyl group and AOPPs significantly after garlic administration. MDA also decreased significantly after tablet usage.

\section{Acknowledgments:}

The authors would like to express their thanks to the Board of Directors of Shahid Sadoughi University of Medical Sciences. 
http://www.ephysician.ir

Trial registration: The protocol of trial was registered at the Iranian clinical trial register (www.irct.ir) with ID: IRCT138811183273N1.

\section{Funding:}

This study funded by Shahid Sadoughi University of Medical Sciences (Yazd, Iran).

\section{Conflict of Interest:}

There is no conflict of interest to be declared.

\section{Authors' contributions:}

All authors contributed to this project and article equally. All authors read and approved the final manuscript.

\section{References:}

1) Shahbazian H. World diabetes day; 2013. J Renal Inj Prev. 2013; 2(4): 123 -4. doi: 10.12861/jrip.2013.39.

2) Elalamy I, Chakroun T, Gerotziafas GT, Petropoulou A, Robert F, Karroum A, et al. Circulating platelet leukocyte aggregates: a marker of microvascular injury in diabetic patients. Thromb Res. 2008; 121(6): 843-8. doi: 10.1016/j.thromres.2007.07.016. PMID: 17825880.

3) Jindal S, Gupta S, Gupta R, Kakkar A, Singh HV, Gupta K, et al. Platelet indices in diabetes mellitus: indicators of diabetic microvascular complications. Hematology. 2011; 16(2): 86-9. doi: 10.1179/102453311X12902908412110.

4) Demirtas L, Degirmenci H, Akbas EM, Ozcicek A, Timuroglu A, Gurel A, et al. Association of hematological indices with diabetes, impaired glucose regulation and microvascular complications of diabetes. Int J Clin Exp Med. 2015; 8(7): 11420-5. PMID: 26379958, PMCID: PMC4565341.

5) Meigs JB, Muller DC, Nathan DM, Blake DR, Andres R. The natural history of progression from normal glucose tolerance to type 2 diabetes in the Baltimore longitudinal study of aging. Diabetes. 2003; 52(6): 1475-84. doi: 10.2337/diabetes.52.6.1475. PMID: 12765960.

6) Levitzky YS, Pencina MJ, D’Agostino RB, Meigs JB, Murabito JM, Vasan RS, et al. Impact of Impaired Fasting Glucose on Cardiovascular Disease. J Am Coll Cardiol. 2008; 51(3): 264-70. doi: 10.1016/j.jacc.2007.09.038.

7) Cho YI, Mooney MP, Cho DJ. Hemorheological disorders in diabetes mellitus. J Diabetes Sci Technol. 2008; 2(6): 1130-8. doi: 10.1177/193229680800200622. PMID: 19885302, PMCID: PMC2769810.

8) Tamariz LJ, Young JH, Pankow JS, Yeh HC, Schmidt MI, Astor B, et al. Blood viscosity and hematocrit as risk factors for type 2 diabetes mellitus: the atherosclerosis risk in communities (ARIC) study. Am J Epidemiol. 2008; 168: 1153-60. doi: 10.1093/aje/kwn243. PMID: 18931370, PMCID: PMC2581671.

9) Biadgo B, Melku M, Abebe SM, Abebe M. Hematological indices and their correlation with fasting blood glucose level and anthropometric measurements in type 2 diabetes mellitus patients in Gondar, Northwest Ethiopia. Diabetes Metab Syndr Obes. 2016; 9: 91-9. doi: 10.2147/DMSO.S97563. PMID: 27042134, PMCID: PMC4801204.

10) Chen LK, Ming-Hsien L, Zhi-Jun C, Shinn-Jang H, Chiou ST. Association of insulin resistance and hematologic parameters: study of a middle-aged and elderly Chinese population in Taiwan. J Chin Med Assoc. 2006; 69(6): 248-53. doi: 10.1016/S1726-4901(09)70251-5. PMID: 16863009.

11) Simmons D. Increased red cell count in diabetes and pre-diabetes. Diabetes Res Clin Pract. 2010; 90(3): e50-3. doi: 10.1016/j.diabres.2010.07.005. PMID: 20701991.

12) Gokulakrishnan K, Deepa R, Sampathkumar R, Balasubramanyam M, Mohan V. Association of leukocyte count with varying degrees of glucose intolerance in Asian Indians: the Chennai Urban Rural Epidemiology Study (CURES-26). Metab Syndr Relat Disord. 2009; 7(3): 205-10. doi: 10.1089/met.2008.0024. PMID: 19284318.

13) Coban E, Kucuktag S, Basyigit S. Platelet activation in subjects with impaired glucose tolerance. Platelets. 2007; 18: 591-4. doi: 10.1080/09537100701609019. PMID: 18041650.

14) Anuurad E, Shiwaku K, Nogi A, Kitajima K, Enkhmaa B, Shimono K, et al. The new BMI criteria for asians by the regional office for the western pacific region of WHO are suitable for screening of overweight to prevent metabolic syndrome in elder Japanese workers. J Occup Health. 2003; 45(6): 335-43. doi: 10.1539/joh.45.335. PMID: 14676412.

15) American Diabetes Association. Diagnosis and Classification of Diabetes Mellitus. Diabetes Care. 2010; 33(Suppl 1): S62-9. doi: 10.2337/dc10-S062. PMID: 20042775, PMCID: PMC2797383. 
16) Tan BT, Nava AJ, George TI. Evaluation of the Beckman Coulter UniCel DxH 800, Beckman Coulter LH 780, and Abbott Diagnostics Cell-Dyn Sapphire hematology analyzers on adult specimens in a tertiary care hospital. Am J Clin Pathol. 2011; 135: 939-51. doi: 10.1309/AJCP1V3UXEIQTSLE. PMID: 21571967.

17) Ezenwaka CE, Jones-Lecointe A, Nwagbara E, Seales D, Okali F. Anemia and kidney dysfunction in Caribbean type 2 diabetic patients. Cardiovasc Diabetol. 2008; 7: 25. doi: 10.1186/1475-2840-7-25.

18) Meisinger C, Rückert IM, Stöckl D, Thorand B, Peters A, Kowall B, et al. Hematological Parameters and Prediabetes and Diabetes in Adults from the General Population: A Cross-Sectional Study. J Diabetes Metab. 2014; 5: 2. doi: 10.4172/2155-6156.1000335.

19) Du X, Zhu B, Hu G, Mao W, Wang S, Zhang H, et al. U-shape association between white blood cell count and the risk of diabetes in young Chinese adults. Diabet Med. 2009; 26(10): 955-60. doi: 10.1111/j.14645491.2009.02801.x. PMID: 19900225.

20) Moradi S, Kerman SR, Rohani F, Salari F. Association between diabetes complications and leukocyte counts in Iranian patients. J Inflamm Res. 2012; 5: 7-11. doi: 10.2147/JIR.S26917. PMID: 22334791, PMCID: PMC3278259.

21) Tong PC, Lee KF, So WY, Ng MH, Chan WB, Lo MK, et al. White blood cell count is associated with macro- and microvascular complications in chinese patients with type 2 diabetes. Diabetes Care. 2004; 27(1): 216-22. doi: 10.2337/diacare.27.1.216. PMID: 14693992.

22) Qiu M, Shen W, Song X, Ju L, Tong W, Wang H, et al. Effects of prediabetes mellitus alone or plus hypertension on subsequent occurrence of cardiovascular disease and diabetes mellitus: longitudinal study. Hypertension. 2015; 65(3): 525-30. doi: 10.1161/HYPERTENSIONAHA.114.04632. PMID: 25624343.

23) Shim WS, Kim HJ, Kang ES, Ahn CW, Lim SK, Lee HC, et al. The association of total and differential white blood cell count with metabolic syndrome in type 2diabetic patients. Diabetes Res Clin Pract. 2006; 73(3): 284-91. doi: 10.1016/j.diabres.2006.02.001. PMID: 16563549.

24) Chung FM, Tsai JC, Chang DM, Shin SJ, Lee YJ. Peripheral total and differential leukocyte count in diabetic nephropathy: the relationship of plasma leptin to leukocytosis. Diabetes Care. 2005; 28(7): 1710-7. doi: 10.2337/diacare.28.7.1710. PMID: 15983324.

25) Dada OA, Uche E, Akinbami A, Odesanya M, John-Olabode S, Adediran A, et al. The relationship between red blood cell distribution width and blood pressure in patients with type 2 diabetes mellitus in Lagos, Nigeria. J Blood Med. 2014; 5: 185-9. doi: 10.2147/JBM.S67989.

26) Malandrino $\mathrm{N}, \mathrm{Wu}$ WC, Taveira TH, Whitlatch HB, Smith RJ. Association between red blood cell distribution width and macrovascular and microvascular complications in diabetes. Diabetologia. 2012; 55(1): 226-35. doi: 10.1007/s00125-011-2331-1.

27) Tesfamariam B, Cohen RA. Free radicals mediate endothelial cell dysfunction caused by elevated glucose. Am J Physiol. 1992; 263(2 Pt 2): H321-6. PMID: 1510128.

28) King GL, Loeken MR. Hyperglycemia-induced oxidative stress in diabetic complications. Histochem Cell Biol. 2004; 122(4): 333-8. doi: 10.1007/s00418-004-0678-9.

29) Gerner RR, Wieser V, Moschen AR, Tilg H. Metabolic inflammation: role of cytokines in the crosstalk between adipose tissue and liver. Can J Physiol Pharmacol. 2013; 91(11): 867-72. doi: 10.1139/cjpp-20130050. PMID: 24117253.

30) Cawood TJ, Buckley U, Murray A, Corbett M, Dillon D, Goodwin B, et al. Prevalence of anaemia in patients with diabetes mellitus. Ir J Med Sci. 2006; 175(2): 25-7. doi: 10.1007/BF03167944. PMID: 16872024.

31) Wang ZS, Song ZC, Bai JH, Li F, Wu T, Qi J, et al. Red blood cell count as an indicator of microvascular complications in Chinese patients with type 2 diabetes mellitus. Vasc Health Risk Manag. 2013; 9: $237-43$. doi: 10.2147/VHRM.S43211. PMID: 23690689, PMCID: PMC3656917.

32) Stevens PE. Anaemia, diabetes and chronic kidney disease: where are we now? J Ren Care. $2012 ; 38$ Suppl 1: 67-77. doi: 10.1111/j.1755-6686.2012.00281.x. 